\title{
Ethanol Ablation of the Thyroid Nodules: 2018 Consensus Statement by the Korean Society of Thyroid Radiology
}

Soo Yeon Hahn, MD, PhD ${ }^{1}$, Jung Hee Shin, MD, $\mathrm{PhD}^{1}$, Dong Gyu Na, MD, PhD ${ }^{2,3}$, Eun Joo Ha, MD, PhD , Hye Shin Ahn, $\mathrm{MD}^{5}$, Hyun Kyung Lim, MD, $\mathrm{PhD}^{6}$, Jeong Hyun Lee, MD, PhD', Jeong Seon Park, MD, $\mathrm{PhD}^{8}$, Ji-hoon Kim, MD, PhD ${ }^{9}$, Jin Yong Sung, MD $^{10}$, Joon Hyung Lee, MD, PhD ${ }^{11}$, Jung Hwan Baek, MD, PhD ${ }^{7}$, Jung Hyun Yoon, MD, PhD ${ }^{12}$, Jung Suk Sim, MD, PhD ${ }^{13}$, Kwang Hwi Lee, MD ${ }^{14}$, Seon Mi Baek, MD ${ }^{15}$, So Lyung Jung, MD, PhD ${ }^{16}$, Yeo Koon Kim, MD ${ }^{17}$, Yoon Jung Choi, MD, PhD ${ }^{18}$; Korean Society of Thyroid Radiology (KSThR) and Korean Society of Radiology

\begin{abstract}
${ }^{1}$ Department of Radiology and Center for Imaging Science, Samsung Medical Center, Sungkyunkwan University School of Medicine, Seoul, Korea; ${ }^{2}$ Department of Radiology, Gangneung Asan Hospital, Gangneung, Korea; ${ }^{3}$ Department of Radiology, Human Medical Imaging and Intervention Center, Seoul, Korea; ${ }^{4}$ Department of Radiology, Ajou University School of Medicine, Suwon, Korea; ${ }^{5}$ Department of Radiology and Thyroid Center, Chung-Ang University Hospital, Chung-Ang University College of Medicine, Seoul, Korea; ${ }^{6}$ Department of Radiology, Soonchunhyang University Seoul Hospital, Soonchunhyang University College of Medicine, Seoul, Korea; ${ }^{7}$ Department of Radiology and Research Institute of Radiology, University of Ulsan College of Medicine, Asan Medical Center, Seoul, Korea; ${ }^{8}$ Department of Radiology, Hanyang University College of Medicine, Hanyang University Hospital, Seoul, Korea; ${ }^{9}$ Department of Radiology, Seoul National University College of Medicine, Seoul, Korea; ${ }^{10}$ Department of Radiology and Thyroid Center, Daerim St. Mary's Hospital, Seoul, Korea; ${ }^{11}$ Department of Radiology, Haeundae Paik Hospital, Inje University School of Medicine, Busan, Korea; ${ }^{12}$ Department of Radiology, Research Institute of Radiological Science, Severance Hospital, Yonsei University College of Medicine, Seoul, Korea; ${ }^{13}$ Department of Radiology, Withsim Clinic, Seongnam, Korea; ${ }^{14}$ Department of Radiology, Sheikh Khalifa Specialty Hospital, Ras Al Khaima, UAE; ${ }^{15}$ Department of Radiology, Haeundae Sharing and Happiness Hospital, Busan, Korea; ${ }^{16}$ Department of Radiology, Seoul St. Mary's Hospital, College of Medicine, The Catholic University of Korea, Seoul, Korea; ${ }^{17}$ Department of Radiology, Seoul National University Bundang Hospital, Seongnam, Korea; ${ }^{18}$ Department of Radiology, Kangbuk Samsung Hospital, Sungkyunkwan University, Seoul, Korea
\end{abstract}

Minimally invasive treatment of symptomatic thyroid nodules is now commonplace. Ethanol ablation (EA) of thyroid cystic nodules has been performed since the 1990s, but there is no global consensus or guideline. Although various limitations of EA have been described, recommendations for practical application are necessary. Therefore, the Task Force Committee of the Korean Society of Thyroid Radiology initiated the present consensus statement and here we provide recommendations for the role of EA in the management of symptomatic thyroid nodules. These recommendations are based on evidence to date from the literature and expert opinion.

Keywords: Thyroid; Thyroid neoplasm; Ethanol ablation; Minimally invasive therapy; Guidelines

\section{INTRODUCTION}

Thyroid nodules are very common in clinical practice; they are discovered by palpation in $3-7 \%$ and by ultrasound (US) in about $50 \%$ of the general population (1). The majority of thyroid nodules are benign and asymptomatic, and benign thyroid nodules are usually managed by only observation and follow-up; however, a minority of them (10-15\%) (2)

Received October 8, 2018; accepted after revision November 5, 2018.

This study was supported by a grant by 2017 Clinical Practice Guideline Research Fund by Korean Society of Radiology \& Korean Society of Thyroid Radiology.

Corresponding author: Jung Hee Shin, MD, PhD, Department of Radiology and Center for Imaging Science, Samsung Medical Center, Sungkyunkwan University School of Medicine, 81 Irwon-ro, Gangnam-gu, Seoul 06351, Korea.

- Tel: (822) 3410-6420 • Fax: (822) 3410-0049•E-mail: jhshin11@skku.edu

This is an Open Access article distributed under the terms of the Creative Commons Attribution Non-Commercial License (https:// creativecommons.org/licenses/by-nc/4.0) which permits unrestricted non-commercial use, distribution, and reproduction in any medium, provided the original work is properly cited. 
increase in size over time and may induce symptoms or cosmetic issues.

Recent guidelines $(3,4)$ do not recommend thyroidstimulating hormone (TSH) suppressive therapy with levothyroxine for benign nodules because the effect of medication in volume reduction of a thyroid nodule is uncertain (5-7) and may result in side effects such as longterm osteoporosis or atrial fibrillation. Surgical excision has been established as a treatment for symptomatic benign thyroid nodules. However, it carries a $2-10 \%$ risk of complications and neck scarring, and may result in hypothyroidism $(8,9)$. Thyroid surgery is also costly and may not be appropriate for patients who have a high risk of surgical morbidity or those who refuse surgery. Therefore, image-guided nonsurgical procedures such as ethanol ablation (EA) and thermal ablation have been proposed as alternative and less invasive approaches for the management of benign symptomatic thyroid nodules (10).

EA is widely used as a nonsurgical treatment usually for cystic (i.e., pure cyst) or predominantly cystic benign thyroid nodules (i.e., cystic portion $>50 \%$ ) (11). Direct injection of ethanol through a needle or a catheter for the purpose of atrophy of a mass in a solid organ is called $E A$, ethanol injection, or ethanol sclerotherapy. The first interventional attempt to treat a thyroid nodule was simple aspiration of a thyroid cyst in 1966 by Crile (12). In 1974, Miller et al. (13) suggested that simple aspiration alone was associated with a high recurrence rate of $58 \%$, which is the limit of this treatment. Thereafter, various sclerosing agents were used to treat recurrent thyroid cysts (14-16). In 1985, Rozman et al. (17) first used ethanol to treat thyroid cysts. In 1990, Livraghi et al. (18) used US for EA of functional thyroid nodules. Subsequently, US-guided EA of benign thyroid nodules was performed by several groups (18-28).

In recent years, EA has also been used to treat recurrent thyroid cancer (29-35). For the treatment of local recurrence of thyroid cancer, surgery should be considered as the firstline treatment option if the recurrence site is confirmed by an imaging technique (3). However, even if recurrent cancer is confirmed, reoperation may be technically difficult if the normal tissue plane is distorted by the previous surgery and the recurrent cancer occurs in an area where scarring with fibrosis has developed. In addition, surgical complications may occur. External-beam radiation therapy can be considered for loco-regional recurrence that is not surgically resectable or for cases with extranodal extension or involvement of soft tissues, particularly in patients without distant metastasis (3). However, external radiation may increase morbidity due to complications $(36,37)$. Therefore, image-guided nonsurgical procedures such as EA or radiofrequency ablation (RFA) have been proposed as alternative therapies for patients who are concerned about the complications of external radiation, refuse external irradiation, may have serious complications following surgery, or who may be at high risk for surgery (29-35, 38-46).

The Korean Society of Thyroid Radiology organized a taskforce to provide recommendations for EA of thyroid nodules and recurrent thyroid cancers in August 2017. The recommendations include sections dealing with indications for $E A$, principle of EA, standard technique, clinical outcomes, postprocedural surveillance and indications for additional ablation, and complications. A PubMed MEDLINE search was performed to retrieve publications from 1990 to December 2017 with the following keywords: ethanol, ablation, injection, sclerotherapy, thyroid nodule, and thyroid carcinoma. Because there are only a few controlled clinical studies (47-49) of EA, recommendations regarding some issues are based on expert opinion. This limitation needs to be overcome in the future by further investigations. The goal of these recommendations is to summarize the best scientific evidence available and provide a consensus expert opinion regarding the use of EA to treat thyroid nodules and recurrent thyroid cancer in clinical practice.

\section{Indications}

\section{Benign Thyroid Nodules}

\section{Cystic and Predominantly Cystic Nodules}

EA can be indicated for the treatment of benign recurrent pure cysts or predominantly cystic nodules causing pressure symptoms or complaints of neck bulging. The efficacy of EA for the management of pure cysts or predominantly cystic nodules has been well documented (24, 28, 50-54). In a completely cystic nodule, EA can achieve a volume reduction of $85-95 \%$. However, in a predominantly cystic nodule, the rate of volume reduction varies from $60 \%$ to $90 \%(24,28)$. Results for predominantly cystic nodules with a solid portion less than $20 \%$ are satisfactory (55).

Simple aspiration is the first treatment option for symptomatic benign pure cysts and predominantly cystic nodules. However, simple aspiration has been shown to have a high recurrence rate of $\leq 58 \%(19,56)$. Therefore, $E A$ is a reasonable approach in patients with recurrent 
cystic fluid accumulation after initial aspiration.

A cytological result obtained from simple aspiration can confirm that the pure cystic or predominantly cystic nodule is benign. In the case of pure cysts, however, cytological results are often nondiagnostic or unsatisfactory, even with repeated cytological examinations. EA can be used to treat recurrent pure cysts, regardless of nondiagnostic results. Meanwhile, in cases of predominantly cystic nodules with typical benign US findings such as a spongiform appearance or intra-cystic comet tail artifact, EA can be performed after at least one benign fine-needle aspiration (FNA) result. In other cases of predominantly cystic nodules with some solid portion, at least two benign FNA results are essential before performing the EA procedure. Recurrence rate of thyroid cysts was reported to decrease to less than $20 \%$ after EA (28).

\section{Hyperfunctioning Thyroid Nodules}

EA has been proposed as an alternative therapy to surgery and radioiodine for hyperfunctioning nodules (5762 ). The size of nodules has been reported to decrease and hyperthyroidism to resolve after EA therapy (63). However, the larger the size of the nodule, the harder it is to achieve a therapeutic effect (60). EA has shown the greatest effectiveness against hyperfunctioning solitary thyroid nodules with a volume less than $30 \mathrm{~mL}$ (57-60). Recent studies reported very good results for hyperfunctioning thyroid nodules with a volume greater than $40 \mathrm{~mL}(64,65)$.

When ethanol is used to treat cystic nodules, ethanol is confined within the cystic space. Therefore, the incidence of complications is low. However, it is difficult to control leakage when ethanol is injected into solid nodules. This may cause unwanted complications (66). In addition, uneven distribution of ethanol in the nodules requires more sessions of treatment than thermal ablation when treating the same sized nodules. Due to these drawbacks, the use of EA in large solid nodules has been limited $(67,68)$.

In recent years, new thermal ablation techniques such as RFA, laser ablation, microwave ablation, and high-intensity focused US have been used to treat thyroid nodules. Many researchers recommend EA for the treatment of cystic thyroid tumors. Thermal ablation is recommended for solid nodules $(66,69-73)$.

\section{Malignant Thyroid Nodules}

\section{Recurrent Thyroid Carcinoma}

Primary treatment for local recurrent thyroid carcinoma is surgery, if indicated, followed by radioactive iodine therapy and/or thyroid hormone therapy. However, if surgery is difficult or serious side effects are likely to occur, US-guided minimally invasive treatments such as RFA or EA can be used as alternatives. Percutaneous EA is a less invasive procedure than surgery for which general anesthesia is required, and repeat procedures are easy to perform and safe, which would decrease the risk of complications (29-35, 74, 75).

Before performing EA, recurrence should be confirmed via US-guided FNA cytology and/or measurement of the washout thyroglobulin (or calcitonin) concentration (11).

Although only a few studies have evaluated the efficacy of EA to treat recurrent thyroid carcinoma, EA has limited effectiveness in terms of complete disappearance of recurrent nodules and a relatively higher recurrence rate during follow-up than RFA (76). Therefore, EA may be recommended for complete ablation in patients with recurrent thyroid carcinoma with three or fewer local recurrent nodules without known distant metastasis, or for palliative purposes in patients with known distant metastases with recurrent tumors that are increasing in size.

EA requires several treatment sessions (1-6 injections) $(29,77)$. The larger the recurrent tumor size, the more treatment sessions are required.

Therefore, based on current evidence $(29,30,33,67,76$, 78-81), EA is an alternative treatment option for locally recurrent thyroid carcinomas in patients who are at high risk of surgery or those who refuse repeated surgeries as well as RFA, depending on the operator's experience and available facilities.

\section{Primary Thyroid Carcinoma}

Since 1993, only three case reports of the use of EA to treat primary thyroid carcinoma have been published (82-84). All treatments were performed in patients with unresectable tumors or in poor medical condition. Evidence for the use of EA to treat primary thyroid carcinoma is therefore lacking, and EA of primary thyroid cancer is not yet recommended.

\section{Principle}

\section{Therapeutic Mechanism}

EA uses ethanol of high purity (95-99\%). Ethanol has several hydrogen bonds in a single molecule and dissolves quickly when it comes into contact with water. Its mechanism of action is a combination of the following 
two effects: 1) coagulative necrosis of tissue due to cell dehydration and protein denaturation due to diffusion, and 2) ischemic necrosis due to small blood vessel thrombus formation and inhibition of enzymatic activity in surrounding tissues $(19,85)$, which may result in fibrosis and atrophy of the nodule. The main mechanism is thought to be coagulative necrosis for thyroid cysts, and ischemic necrosis for solid thyroid nodules (86).

\section{Standard Technique}

\section{Pre-Procedure Evaluation}

It is important to characterize the thyroid nodule and evaluate the surrounding critical anatomical structures through a preprocedural US examination. The size, proportion of solid component, vascularity, and internal contents of the cystic component should be carefully evaluated on US. Three orthogonal diameters (the largest and two diameters perpendicular to it) should be measured by US and nodule volume could be calculated using the equation $V=\pi a b c / 6$ where $V$ is volume, $a$ is the maximum diameter, and $b$ and $c$ are the other two perpendicular diameters. A laboratory test usually includes a thyroid function test (measurement of thyrotropin [TSH], triiodothyronine, and free thyroxine) $(87,88)$, while a blood coagulation battery (bleeding time, prothrombin time, and activated partial thromboplastin time) may be considered based on the patient's medical history or hemorrhagic risk. Nodule-related symptom score on a $10-\mathrm{cm}$ visual analogue scale (0-10) and cosmetic score (1, no palpable mass; 2, a palpable mass but no cosmetic problems; 3 , cosmetic problems on swallowing only; 4, readily detected cosmetic problems) should be measured by patients and physician, respectively, as baseline data. An explanation of the procedure and informed consent must be provided before the procedure. Informed consent should include the possibility of adverse events (pain or voice changes are symptoms of nerve injury caused by leakage).

\section{Procedures for Benign Thyroid Nodules}

Procedures are generally performed on an outpatient basis. A 16-20 G needle, 10-25 mL syringe, and 95-99\% ethanol are necessary for the procedure. There are some differences depending on the operator, but the general method is as follows.

The patient is placed in a supine position on the bed with mild neck extension. After skin sterilization, local anesthetic (1-2\% lidocaine) is usually injected at the skin puncture site. Depending on the viscosity of the contents in the cyst, a single 16-20 G needle is inserted into the center of the cystic area under US guidance. A trans-isthmic approach route is recommended to prevent a change in the position of the needle tip and ethanol leakage when the patient swallows or talks (Fig. 1). As much internal fluid is aspirated as possible and residual debris or colloids are removed by saline irrigation. High viscosity fluid of colloid cysts may be difficult to aspirate. Several studies on the evacuation of viscous cystic thyroid nodules have used normal saline irrigation to decrease viscosity, repeated ethanol injection into the nodules with an interval period, a large-bore needle, or even a large pigtail catheter connected to a suction pump (89-93). Then, the operator
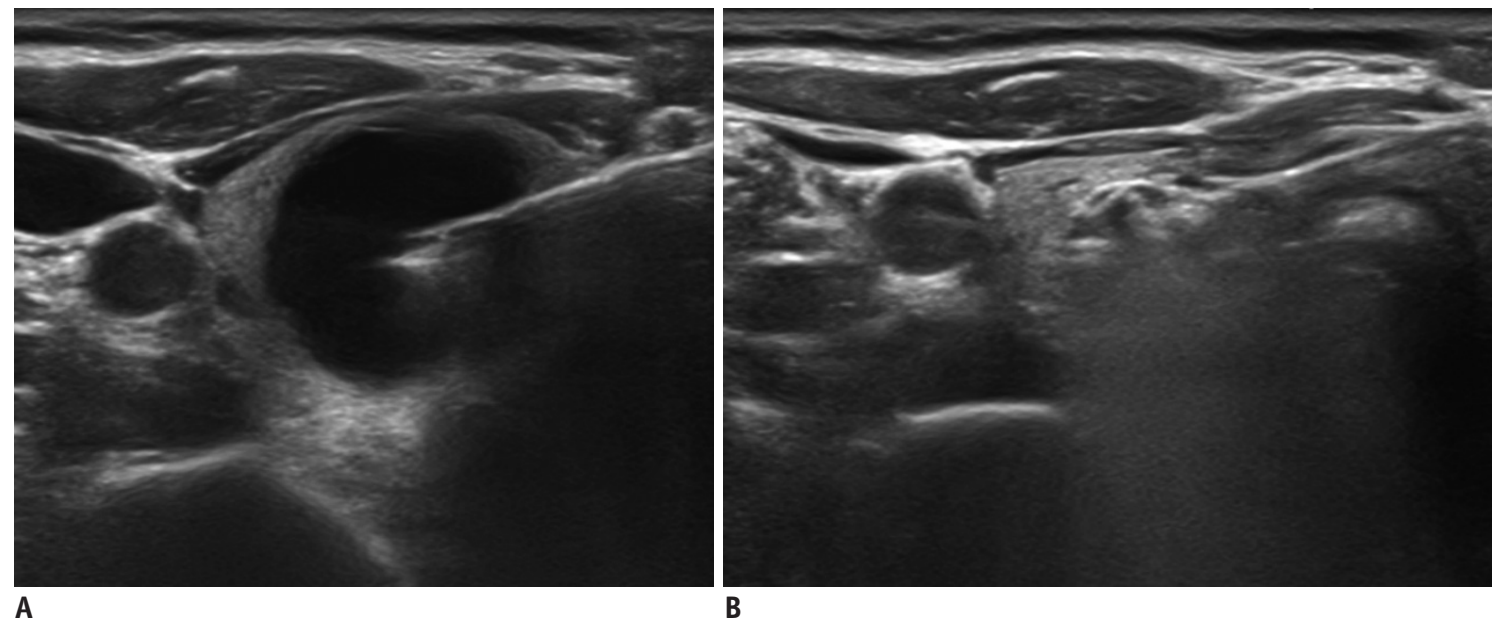

Fig. 1. EA for benign recurrent cyst in right thyroid gland.

A. 18-gauge needle inserted into center of cystic area via trans-isthmic approach route. B. After aspiration of internal fluid, ethanol was slowly injected into cystic space. $E A$ = ethanol ablation 
slowly injects an appropriate amount of 95-99\% ethanol into the cystic space. The amount of ethanol injected depends on the amount of aspirated material in the nodule; approximately $50 \%$ of the aspirate volume is usually injected. Total retention amount of ethanol is empirically recommended not to exceed $10 \mathrm{~mL}$, even for large-sized nodules $(19,28,51,56,94)$. However, if injected ethanol is to be removed after the procedure, a larger amount of ethanol can be used. A sufficient consensus has not yet been established regarding the total amount of ethanol to use for injection. The exact ethanol amount should be tailored according to the size and internal content of the lesion, the opinion of the operator during the procedure, and patient compliance. An ethanol retention time of 2 minutes was found to be sufficient by Kim et al. (95), because ethanol reacts rapidly with cells. However, there is no consensus on whether ethanol should be re-aspirated or not after the procedure. Several studies have suggested that a short retention (at least 2 minutes) and complete removal of ethanol is preferable because longer ethanol retention times may increase patient inconvenience and complications due to possible leakage of ethanol $(95,96)$. This also has the advantage that the patient's satisfaction is high, because the size of the nodule is reduced immediately after the procedure. Kim et al. (53) reported that there was no difference in complication or success rated between groups in which ethanol was not aspirated or aspirated after injection. Therefore, ethanol injection with or without aspiration may be used depending on the operator's preference.

If the patient complains of pain during injection, the operator should stop the injection and check for perithyroidal leakage. Perithyroidal leakage is less likely if the needle tip is well located at the center of the lesion and excessive ethanol is not injected. If excessive amounts of ethanol are used, it may be helpful to re-aspirate the injected ethanol for pain relief. When the procedure is finished, quickly pull out the needle and lightly compress the puncture site for 5-10 minutes.

\section{Procedures for Recurrent Thyroid Carcinoma}

A $1 \mathrm{~mL}$ syringe with a 22-25 $\mathrm{G}$ needle is usually used for EA of recurrent thyroid cancer (30-33, 67). Under US guidance, after local anesthesia, $0.1-1 \mathrm{~mL}$ ethanol (per session) is injected beginning at the deepest and most peripheral portion of the recurrent cancer and moving to the superficial area. Immediately after the injection of ethanol, the treated area becomes echogenic (Fig. 2). The position of the needle is important to safely and effectively inject ethanol into the entire recurrent thyroid cancer lesion. Doppler US is useful for identifying untreated vascular areas and subsequent repositioning of the needle. Ethanol injections are continued until the entire recurrent cancer turned out to be transient echogenic area (32). If leakage to the outside of the lesion is detected on US or if severe pain occurs, ethanol injection must be terminated immediately.

\section{Clinical Outcomes}

\section{Benign Thyroid Nodules}

Current evidence supports the use of EA as a firstline treatment for pure cysts and predominantly cystic

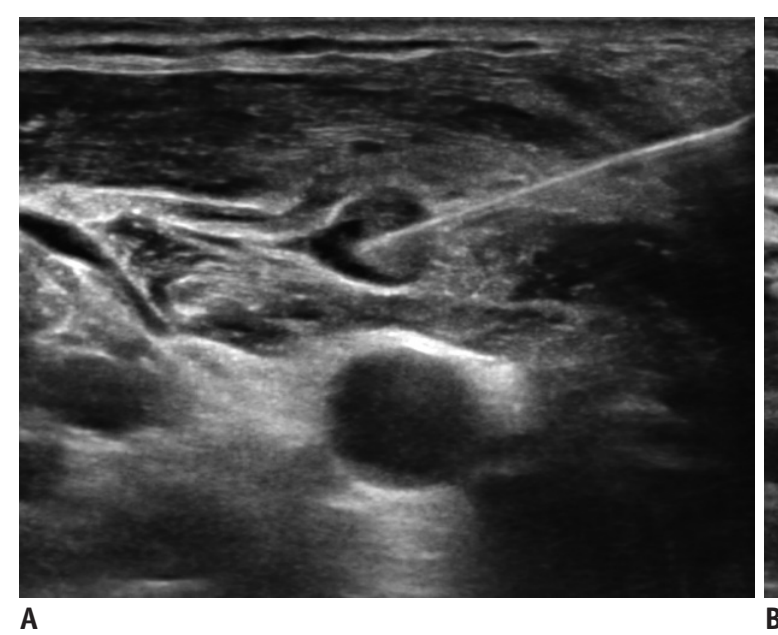

A

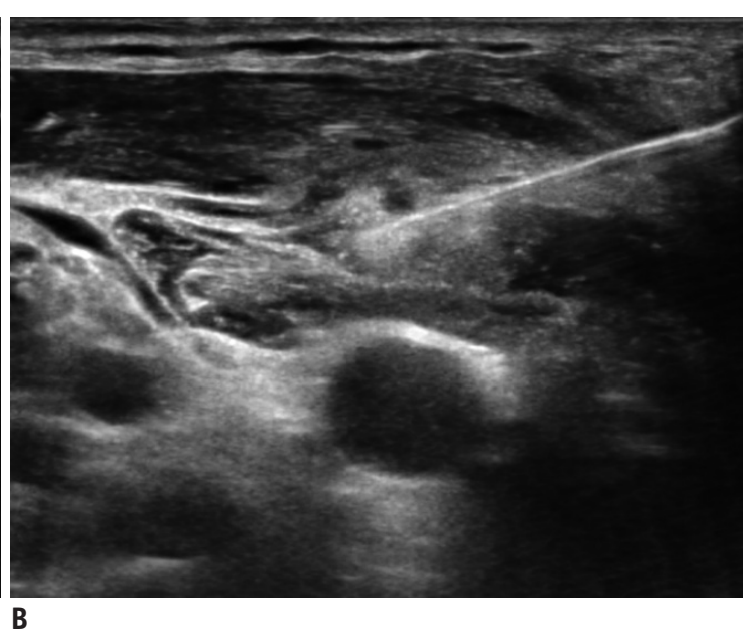

B

Fig. 2. EA for recurrent papillary thyroid carcinoma in right lateral neck.

A. 23-gauge needle inserted into most peripheral portion of recurrent cancer. B. Immediately after injection of ethanol, treated area became echogenic. 
thyroid nodules $(24,28,50-54)$. Clinical outcomes of EA for benign nodules are evaluated by volume reduction and improvement in clinical problems (i.e., improvement in cosmetic problems or pressure symptoms) $(50,56,90$, $93,94,97)$. During the follow-up period, a treated nodule volume of less than $1 \mathrm{~mL}$ should be considered treatment success $(95,98,99)$. Previous studies have reported a $38-98.5 \%$ volume reduction after EA of benign thyroid nodules $(24,52,54,56,92-94,99-102), 85-98.5 \%$ volume reduction after EA of cystic nodules $(54,56,93,94,99)$, 64-73.2\% after EA of predominantly cystic nodules (52, $92,100)$, and $38-47 \%$ after EA of solid nodules $(24,52$, $101,102)$. EA is very effective for cystic thyroid nodules, and has a low recurrence rate of less than $20 \%$ (28). In predominantly cystic nodules, recurrence has been reported in large or vascular predominantly cystic nodules (95). Despite the effectiveness of EA in treating pure cysts and predominantly cystic thyroid nodules, about $5-25 \%$ of patients have nodules refractory to EA $(28,53,56$, $65)$. A recent study reported that EA was less effective in nodules with more than $20 \%$ solid component (55). In these recurrent nodules, RFA has been proposed as the next step treatment $(55,103)$ because RFA achieves $91-92 \%$ volume reduction and improvement in clinical problems in patients with incompletely resolved clinical problems after EA. Although EA has been used in solid thyroid nodules, the efficacy of EA in these nodules is limited because of the limited volume reduction and requirement for several treatment sessions $(52,55,96)$.

In a 10-year follow-up study of patients with cystic thyroid nodules (97), EA resulted in a 50\% volume reduction in $94 \%$ (92 of 98) of patients. Moreover, all patients showed a significant improvement in cyst-related symptoms due to the reduction in cyst volume. Only $6.5 \%$ (6 of 92) of patients had a recurrent nodule at the 9-year followup. In that study, the mean index cyst volume was $35.2 \mathrm{~mL}$ (median, $30.5 \mathrm{~mL}$ ) and the mean number of EA sessions per patient was 1.8 .

In another study from Korea (49), EA was used to treat 107 predominantly cystic thyroid nodules and patients were followed-up for 55 months. The recurrence rate was $18.7 \%$ (20 of 107) at the 1-month follow-up. Among 87 patients with non-recurrence, $24.1 \%$ (21 of 87) showed delayed recurrence. Therefore, recurrence is also far more common for predominantly cystic nodules treated with EA than pure cysts in long term follow up (97).

\section{Success-Related Factors}

Although EA is effective and safe for both pure cysts and predominantly cystic nodules, it is more effective for pure cysts than predominantly cystic nodules in terms of volume reduction, therapeutic success, and requirement for additional treatment $(52,57,95)$. In the case of cystic nodules, the volume of ethanol injected is related to the amount of volume reduction; generally $50 \%$ of the aspirated volume is recommended $(47,52,90,95)$. Vascularity in a solid component is one of the major factors that affects volume reduction of predominantly cystic nodules after EA. According to previous studies $(52,55,57,62,95,103)$, solid components are more resistant to ethanol than cystic components, and the vascularity of solid components may cause the drainage of ethanol, thus limiting the success of EA. In contrast, intranodular echo-staining can be observed during EA when the nodule has poor venous washout of the injected ethanol, and this is considered a sign predictive of the success of EA (48). The vascular solid component can also cause internal bleeding in the nodules during the follow-up period after EA $(95,96)$. For both pure cysts and predominantly cystic nodules, the effectiveness of EA can be reduced by a large initial volume $(>10 \mathrm{~mL}$ ) or insufficient retention time of ethanol ( $<2$ minutes) $(18,24,25,28,49$, $50,60,92,95)$. To successfully treat viscous cystic nodules with $\mathrm{EA}$, vigorous aspiration using a large-bore needle or normal saline irrigation is required as a pre-step for evacuation $(47,52,90,92,95)$. The success-related factors of EA include the nature of the nodule itself (proportion of solid portion, vascularity, and initial volume), intranodular echo-staining during the procedure, retention time of ethanol and the sufficient evacuation of internal content before injection.

\section{Recurrent Thyroid Cancer}

Since Lewis et al. (30) in 2002, a few studies have reported favorable outcomes after EA treatment of recurrent thyroid cancers (29, 31-35).

In four recent studies with a mean follow-up period ranging from 28.2 months to 5.4 years, three studies reported size reduction in $92.7-100 \%$ of cases $(29,33,34)$. In contrast, the study by Guenette et al. (35) reported local progression in $23.8 \%$ of cases. Hay et al. (34) and Heilo et al. (33) reported $45.9 \%$ and $66.1 \%$ complete disappearance rates, respectively. In contrast, Hay et al. (34) and Kim et al. (29) reported recurrence at sites other than the ethanol ablation sites. There were local recurrences at ablation sites 
in $5.5 \%$ and $23.8 \%$ of cases enrolled by Heilo et al. (33) and Guenette et al. (35), respectively $(29,34)$. In these four studies, the number of treatment sessions varied from two to six. Serum thyroglobulin level fell in 19 of $22(86 \%)$ cases without thyroglobulin autoantibodies in the study by Hay et al. (34).

Concordantly, Kim et al. (77) reported an increase in tumor size in $17.1 \%$ of cases while there was no change in size in $24.4 \%$ of cases after EA for locally recurrent papillary thyroid carcinoma based on a minimum 60 months of follow-up.

According to the comparison meta-analysis of RFA and EA performed by Suh et al. (76), RFA tended to result in greater volume reduction and a greater complete disappearance rate than EA, while EA tended to show a higher recurrence rate and a higher reduction rate of serum thyroglobulin level. Fontenot et al. (80) compared surgery and $E A$ and reported that the success rate of surgery was higher but local recurrence at the treated site was similar for the two methods.

Studies reporting the use of EA to treat recurrent thyroid cancers are still limited in number making it difficult to generalize outcomes. Further systematic studies with greater numbers of cases are warranted.

\section{Postprocedural Surveillance and Indications for Additional Ablation of Benign Thyroid Nodules}

Imaging surveillance after EA is usually performed at 1-6 months after ablation (51-53, 57, 92). Treatment outcomes for EA are excellent for thyroid nodules, with a mean volume reduction of $65-96.7 \%$ reported for cystic thyroid nodules after a single session of EA $(51-53,57)$. If there are persistent symptoms or a continuously growing cyst, additional EA sessions can be performed. If more than $1 \mathrm{~mL}$ of cystic contents remains after three consecutive ablation sessions, treatments other than EA should be considered if required (26).

For autonomously functioning thyroid nodules, normalization of thyroid hormone levels is the therapeutic goal for EA rather than a decrease in nodule volume. Therefore, serum thyroid function tests, including measurement of TSH level and radioisotope scans are needed in addition to follow-up US examinations $(25,26$, $50,57,58)$. Consistent monitoring of thyroid function is required for patients with functioning thyroid nodules, and post-ablation surveillance for 6 months or more is required in these patients.

\section{Complications}

\section{Benign Thyroid Nodules}

EA is a safe treatment option for cystic thyroid nodules and complications are mostly mild and transient, if performed by a person familiar with US-guided procedures $(87,88)$. Localized pain in the puncture site is most common, and hematoma, facial flushing, drunken sense, hoarseness, dyspnea, and temporary hyperthyroidism may occur $(57,95)$. Most patients complain of mild pain lasting from several minutes to several hours immediately after the procedure. Patients can recover from this pain spontaneously or the pain can be controlled by analgesics. Hematoma is a common complication associated with pain (52). It occurs when vessels in the thyroid capsule are damaged by the needle at the time of puncture (57). However, if the puncture site is tightly compressed for 10 minutes after the procedure, hematoma can be prevented.

\section{Recurrent Thyroid Cancer}

Based on a systemic review of the use of EA or RFA to treat recurrent thyroid cancer, the pooled proportion of the complication rate of EA was lower than that of RFA $(0.8 \%$ vs. $5.8 \%)$, although this difference was not significant $(p=$ 0.8479 ) (76). Several previous investigations have reported the complications of EA of recurrent thyroid cancer (29-32, $34,35,75,78,104)$ (Table 1). Potential complications of EA include local pain or discomfort, hoarseness, radiating pain to the teeth, jaw, head and chest, and tumor implantation through the needle track (78). Delayed complications have not been reported in studies that had performed long-term follow-up (mean, 74 months) $(34,77)$.

Local pain or discomfort occurs during injection of ethanol in most cases. Most patients experience mild pain or discomfort at the puncture site, which lasts from several minutes to several hours during or/and immediately after the procedure. This pain can resolve spontaneously or be controlled by analgesics. It can be prevented by sufficient injection of lidocaine to perilesional soft tissue and slow injection of ethanol within the target lesion only.

Hoarseness is an important complication that results from damage to the recurrent laryngeal nerve or vagus nerve. Hoarseness occurs frequently when the target lesion is located in the thyroid bed or around the carotid sheath. Most cases with hoarseness are transient and last from 
Table 1. Complications of Ethanol Ablation to Treat Recurrent Thyroid Cancer

\begin{tabular}{|c|c|c|c|c|c|c|c|c|c|}
\hline \multirow[b]{2}{*}{ Number } & \multirow[b]{2}{*}{ Publications, Year } & \multirow[b]{2}{*}{ Authors } & \multirow{2}{*}{$\begin{array}{l}\text { Number of } \\
\text { Patients }\end{array}$} & \multirow{2}{*}{$\begin{array}{c}\text { Number of } \\
\text { Treated } \\
\text { Lesions }\end{array}$} & \multirow{2}{*}{$\begin{array}{c}\text { Mean } \\
\text { Follow-Up } \\
\text { (Months) }\end{array}$} & \multicolumn{4}{|c|}{ Complications } \\
\hline & & & & & & $\begin{array}{l}\text { Mild Pain or } \\
\text { Discomfort }\end{array}$ & $\begin{array}{l}\text { Radiating } \\
\text { Pain }\end{array}$ & $\begin{array}{c}\text { Transient } \\
\text { Hoarseness }\end{array}$ & $\begin{array}{l}\text { Permanent } \\
\text { Hoarseness }\end{array}$ \\
\hline 1 & $\begin{array}{l}\text { Am J Roentgenol, } \\
2002\end{array}$ & Lewis et al. (30) & 14 & 29 & 18 & Most cases & $\begin{array}{c}\text { Several } \\
\text { cases }\end{array}$ & 0 & 0 \\
\hline 2 & Ann Surg, 2006 & Monchik et al. (31) & 6 & 6 & 18.7 & N/A & N/A & 1 & 0 \\
\hline 3 & Thyroid, 2007 & Lim et al. (32) & 16 & 24 & 24 & 16 & N/A & 1 & 0 \\
\hline 4 & Eur Radiol, 2008 & Kim et al. (29) & 27 & 47 & 26 & $\begin{array}{l}73 / 100 \text { sessions } \\
(73 \%)\end{array}$ & N/A & 1 & 0 \\
\hline 5 & $\begin{array}{l}\text { J Clin Endocrinol } \\
\text { Metab, } 2011\end{array}$ & Heilo et al. (33) & 63 & 109 & 38.4 & N/A & N/A & N/A & 0 \\
\hline 6 & Surgery, 2013 & Hay et al. (34) & 25 & 37 & 65 & Most cases & N/A & 1 & 0 \\
\hline 7 & $\begin{array}{l}\text { J Vasc Interv Radiol, } \\
2013\end{array}$ & Guenette et al. (35) & N/A & 21 & 38.5 & N/A & 0 & 0 & 0 \\
\hline 8 & Endocrine, 2014 & Vannucchi et al. (75) & 3 & 4 & 2 & 3 & 0 & 0 & 0 \\
\hline
\end{tabular}

several days to weeks, and recover spontaneously within 3-6 months. Permanent hoarseness has not been reported in cases with recurrent thyroid cancer treated by EA (81). The cause of nerve injury is local spillage of ethanol into the surrounding soft tissue. To prevent this complication, the needle tip should be accurately positioned within the lesion and an extremely small amount of ethanol should initially be injected (32). The injection of ethanol should be discontinued if ethanol spillage is detected on real time US or if the patient complains of considerable pain during ethanol injection. The vagus nerve is also a critical structure related to hoarseness (81). It can be easily identified on US and is located in the carotid space, especially between the carotid artery and internal jugular vein posteriorly. The operator should identify its location and variations during US examination to treat recurrent thyroid cancer located near the carotid space.

Tumor implantation through the needle track is a very rare complication of EA in cases with recurrent thyroid cancer. A case of cutaneous implantation of papillary thyroid cancer originating from a metastatic lymph node in the left paratracheal area that occurred a few months after EA was reported (104). Because this rare complication is clinically relevant, physicians should take into account that this can occur months to years after EA.

Various complications of US-guided EA related to treatment for recurrent thyroid cancers can develop. The operator should have knowledge of these complications and technical tips to avoid procedural-related complications.

\section{CONCLUSION}

EA should be the first option for the treatment of pure cysts and predominantly cystic nodules that are not treated with simple aspiration. EA of solid nodules has limited therapeutic effect and may require multiple sessions.

Long-term outcomes of EA treatment of recurrent papillary thyroid carcinomas indicate that EA is a secondary treatment option with some limitations, even though it can successfully decrease tumor volume.

Unlike surgery, EA is a safe procedure that is easy to repeat, is inexpensive, can be performed easily on an outpatient basis, and has only transient side effects. The present consensus statement provided here will help promote the clinical application of EA.

\section{Conflicts of Interest}

The authors have no potential conflicts of interest to disclose.

\section{ORCID iDs}

Jung Hee Shin

https://orcid.org/0000-0001-6435-7357

Soo Yeon Hahn

https://orcid.org/0000-0002-4099-1617

\section{REFERENCES}

1. Gharib H, Papini E. Thyroid nodules: clinical importance, assessment, and treatment. Endocrinol Metab Clin North Am 2007;36:707-735, vi 
2. Durante C, Costante G, Lucisano G, Bruno R, Meringolo D, Paciaroni $\mathrm{A}$, et al. The natural history of benign thyroid nodules. JAMA 2015;313:926-935

3. Haugen BR, Alexander EK, Bible KC, Doherty GM, Mandel SJ, Nikiforov YE, et al. 2015 American Thyroid Association management guidelines for adult patients with thyroid nodules and differentiated thyroid cancer: the American Thyroid Association guidelines task force on thyroid nodules and differentiated thyroid cancer. Thyroid 2016;26:1-133

4. Gharib H, Papini E, Garber JR, Duick DS, Harrell RM, Hegedüs $\mathrm{L}$, et al. American Association of Clinical Endocrinologists, American College of Endocrinology, and Associazione Medici Endocrinologi medical guidelines for clinical practice for the diagnosis and management of thyroid nodules--2016 update. Endocr Pract 2016;22:622-639

5. Zelmanovitz F, Genro S, Gross JL. Suppressive therapy with levothyroxine for solitary thyroid nodules: a double-blind controlled clinical study and cumulative meta-analyses. J Clin Endocrinol Metab 1998;83:3881-3885

6. Wemeau JL, Caron P, Schvartz C, Schlienger JL, Orgiazzi $\mathrm{J}$, Cousty $\mathrm{C}$, et al. Effects of thyroid-stimulating hormone suppression with levothyroxine in reducing the volume of solitary thyroid nodules and improving extranodular nonpalpable changes: a randomized, double-blind, placebocontrolled trial by the French Thyroid Research Group. J Clin Endocrinol Metab 2002;87:4928-4934

7. Castro MR, Caraballo PJ, Morris JC. Effectiveness of thyroid hormone suppressive therapy in benign solitary thyroid nodules: a meta-analysis. J Clin Endocrinol Metab 2002;87:4154-4159

8. Bergenfelz A, Jansson S, Kristoffersson A, Mårtensson $H$, Reihnér $E$, Wallin $G$, et al. Complications to thyroid surgery: results as reported in a database from a multicenter audit comprising 3,660 patients. Langenbecks Arch Surg 2008;393:667-673

9. Kandil E, Krishnan B, Noureldine SI, Yao L, Tufano RP. Hemithyroidectomy: a meta-analysis of postoperative need for hormone replacement and complications. ORL J Otorhinolaryngol Relat Spec 2013;75:6-17

10. Hegedüs L. Therapy: a new nonsurgical therapy option for benign thyroid nodules? Nat Rev Endocrinol 2009;5:476-478

11. Shin JH, Baek JH, Chung J, Ha EJ, Kim JH, Lee YH, et al. Ultrasonography diagnosis and imaging-based management of thyroid nodules: revised Korean Society of Thyroid Radiology consensus statement and recommendations. Korean J Radiol 2016;17:370-395

12. Crile G Jr. Treatment of thyroid cysts by aspiration. Surgery 1966;59:210-212

13. Miller JM, Zafar SU, Karo JJ. The cystic thyroid nodule. Recognition and management. Radiology 1974;110:257-261

14. Sykes D. The solitary thyroid nodule. Br J Surg 1981;68:510512

15. Hegedüs L, Hansen JM, Karstrup S, Torp-Pedersen S, Juul N. Tetracycline for sclerosis of thyroid cysts. A randomized study. Arch Intern Med 1988;148:1116-1118

16. Ryan WG, Dwarakanathan A. Minor complication of thyroid cyst sclerosis with tetracycline. Arch Intern Med 1986;146:201-202

17. Rozman B, Bencezigman Z, Tomicbrzac H, Skreb F, Pavlinovic Z, Simonovic I. Sclerosation of thyroid cysts by ethanol. Periodicum Biologorum 1990;91:453

18. Livraghi T, Paracchi A, Ferrari C, Reschini E, Macchi RM, Bonifacino A. Treatment of autonomous thyroid nodules with percutaneous ethanol injection: 4-year experience. Radiology 1994;190:529-533

19. Yasuda K, Ozaki 0, Sugino K, Yamashita T, Toshima K, Ito K, et al. Treatment of cystic lesions of the thyroid by ethanol instillation. World J Surg 1992;16:958-961

20. Martino E, Murtas ML, Loviselli A, Piga M, Petrini L, Miccoli $P$, et al. Percutaneous intranodular ethanol injection for treatment of autonomously functioning thyroid nodules. Surgery 1992;112:1161-1164; discussion 1164-1165

21. Papini E, Panunzi C, Pacella CM, Bizzarri G, Fabbrini $R$, Petrucci $L$, et al. Percutaneous ultrasound-guided ethanol injection: a new treatment of toxic autonomously functioning thyroid nodules? J Clin Endocrinol Metab 1993;76:411-416

22. Goletti 0, Monzani F, Lenziardi M, Lippolis PV, De Negri F, Caraccio N, et al. Cold thyroid nodules: a new application of percutaneous ethanol injection treatment. J Clin Ultrasound 1994;22:175-178

23. Bennedbaek FN, Hegedüs L. Alcohol sclerotherapy for benign solitary solid cold thyroid nodules. Lancet 1995;346:1227

24. Bennedbaek FN, Karstrup S, Hegedüs, L. Percutaneous ethanol injection therapy in the treatment of thyroid and parathyroid diseases. Eur J Endocrinol 1997;136:240-250

25. Lippi F, Ferrari C, Manetti L, Rago T, Santini F, Monzani F, et al. Treatment of solitary autonomous thyroid nodules by percutaneous ethanol injection: results of an Italian multicenter study. The multicenter study group. J Clin Endocrinol Metab 1996;81:3261-3264

26. Papini E, Pacella CM, Verde G. Percutaneous ethanol injection (PEI): what is its role in the treatment of benign thyroid nodules? Thyroid 1995;5:147-150

27. Zingrillo M, Collura D, Ghiggi MR, Nirchio V, Trischitta V. Treatment of large cold benign thyroid nodules not eligible for surgery with percutaneous ethanol injection. J Clin Endocrinol Metab 1998;83:3905-3907

28. Bennedbaek FN, Hegedüs L. Treatment of recurrent thyroid cysts with ethanol: a randomized double-blind controlled trial. J Clin Endocrinol Metab 2003;88:5773-5777

29. Kim BM, Kim MJ, Kim EK, Park SI, Park CS, Chung WY. Controlling recurrent papillary thyroid carcinoma in the neck by ultrasonography-guided percutaneous ethanol injection. Eur Radiol 2008; 18:835-842

30. Lewis BD, Hay ID, Charboneau JW, McIver B, Reading CC, Goellner JR. Percutaneous ethanol injection for treatment of cervical lymph node metastases in patients with papillary 
thyroid carcinoma. AJR Am J Roentgenol 2002;178:699-704

31. Monchik JM, Donatini G, Iannuccilli J, Dupuy DE.

Radiofrequency ablation and percutaneous ethanol injection treatment for recurrent local and distant well-differentiated thyroid carcinoma. Ann Surg 2006;244:296-304

32. Lim CY, Yun JS, Lee J, Nam KH, Chung WY, Park CS. Percutaneous ethanol injection therapy for locally recurrent papillary thyroid carcinoma. Thyroid 2007;17:347-350

33. Heilo A, Sigstad E, Fagerlid KH, Håskjold OI, Grøholt KK, Berner $A$, et al. Efficacy of ultrasound-guided percutaneous ethanol injection treatment in patients with a limited number of metastatic cervical lymph nodes from papillary thyroid carcinoma. J Clin Endocrinol Metab 2011;96:27502755

34. Hay ID, Lee RA, Davidge-Pitts C, Reading CC, Charboneau JW. Long-term outcome of ultrasound-guided percutaneous ethanol ablation of selected "recurrent" neck nodal metastases in 25 patients with TNM stages III or IVA papillary thyroid carcinoma previously treated by surgery and 131I therapy. Surgery 2013;154:1448-1454; discussion 1454-1455

35. Guenette JP, Monchik JM, Dupuy DE. Image-guided ablation of postsurgical locoregional recurrence of biopsy-proven well-differentiated thyroid carcinoma. J Vasc Interv Radiol 2013;24:672-679

36. Lee N, Tuttle M. The role of external beam radiotherapy in the treatment of papillary thyroid cancer. Endocr Relat Cancer 2006;13:971-977

37. Shaha AR. Implications of prognostic factors and risk groups in the management of differentiated thyroid cancer. Laryngoscope 2004;114:393-402

38. Dupuy DE, Monchik JM, Decrea C, Pisharodi L. Radiofrequency ablation of regional recurrence from welldifferentiated thyroid malignancy. Surgery 2001;130:971-977

39. Baek JH, Kim YS, Sung JY, Choi H, Lee JH. Locoregional control of metastatic well-differentiated thyroid cancer by ultrasound-guided radiofrequency ablation. AJR Am J Roentgenol 2011;197:W331-W336

40. Long B, Li L, Yao L, Chen S, Yi H, Ye X, et al. Combined use of radioiodine therapy and radiofrequency ablation in treating postsurgical thyroid remnant of differentiated thyroid carcinoma. J Cancer Res Ther 2015;11 Suppl:C244-C247

41. Park KW, Shin JH, Han BK, Ko EY, Chung JH. Inoperable symptomatic recurrent thyroid cancers: preliminary result of radiofrequency ablation. Ann Surg Oncol 2011;18:2564-2568

42. Zhao Q, Tian G, Kong D, Jiang T. Meta-analysis of radiofrequency ablation for treating the local recurrence of thyroid cancers. J Endocrinol Invest 2016;39:909-916

43. Wang L, Ge M, Xu D, Chen L, Qian C, Shi K, et al. Ultrasonography-guided percutaneous radiofrequency ablation for cervical lymph node metastasis from thyroid carcinoma. J Cancer Res Ther 2014;10 Suppl:C144-C149

44. Lee SJ, Jung SL, Kim BS, Ahn KJ, Choi HS, Lim DJ, et al. Radiofrequency ablation to treat loco-regional recurrence of well-differentiated thyroid carcinoma. Korean J Radiol 2014; 15:817-826

45. Lim HK, Baek JH, Lee JH, Kim WB, Kim TY, Shong YK, et al. Efficacy and safety of radiofrequency ablation for treating locoregional recurrence from papillary thyroid cancer. Eur Radiol 2015;25:163-170

46. Kim JH, Yoo WS, Park YJ, Park DJ, Yun TJ, Choi SH, et al. Efficacy and safety of radiofrequency ablation for treatment of locally recurrent thyroid cancers smaller than $2 \mathrm{~cm}$. Radiology 2015;276:909-918

47. Sung JY, Baek JH, Kim KS, Lee D, Yoo H, Kim JK, et al. Single-session treatment of benign cystic thyroid nodules with ethanol versus radiofrequency ablation: a prospective randomized study. Radiology 2013;269:293-300

48. Baek JH, Ha EJ, Choi YJ, Sung JY, Kim JK, Shong YK. Radiofrequency versus Ethanol Ablation for Treating Predominantly cystic thyroid nodules: a randomized clinical trial. Korean J Radiol 2015;16:1332-1340

49. Suh CH, Baek JH, Ha EJ, Choi YJ, Lee JH, Kim JK, et al. Ethanol ablation of predominantly cystic thyroid nodules: evaluation of recurrence rate and factors related to recurrence. Clin Radiol 2015;70:42-47

50. Monzani F, Caraccio N, Goletti 0, Lippolis PV, Casolaro A, Del Guerra P, et al. Five-year follow-up of percutaneous ethanol injection for the treatment of hyperfunctioning thyroid nodules: a study of 117 patients. Clin Endocrinol (Oxf) 1997;46:9-15

51. Verde G, Papini E, Pacella CM, Gallotti C, Delpiano S, Strada S, et al. Ultrasound guided percutaneous ethanol injection in the treatment of cystic thyroid nodules. Clin Endocrinol (Oxf) 1994;41:719-724

52. Kim JH, Lee HK, Lee JH, Ahn IM, Choi CG. Efficacy of sonographically guided percutaneous ethanol injection for treatment of thyroid cysts versus solid thyroid nodules. AJR Am J Roentgenol 2003;180:1723-1726

53. Kim DW, Rho MH, Kim HJ, Kwon JS, Sung YS, Lee SW. Percutaneous ethanol injection for benign cystic thyroid nodules: is aspiration of ethanol-mixed fluid advantageous? AJNR Am J Neuroradiol 2005;26:2122-2127

54. Valcavi R, Frasoldati A. Ultrasound-guided percutaneous ethanol injection therapy in thyroid cystic nodules. Endocr Pract 2004;10:269-275

55. Jang SW, Baek JH, Kim JK, Sung JY, Choi H, Lim HK, et al. How to manage the patients with unsatisfactory results after ethanol ablation for thyroid nodules: role of radiofrequency ablation. Eur J Radiol 2012;81:905-910

56. Monzani F, Lippi F, Goletti 0, Del Guerra P, Caraccio N, Lippolis PV, et al. Percutaneous aspiration and ethanol sclerotherapy for thyroid cysts. J Clin Endocrinol Metab 1994; 78:800-802

57. Guglielmi R, Pacella CM, Bianchini A, Bizzarri G, Rinaldi R, Graziano FM, et al. Percutaneous ethanol injection treatment in benign thyroid lesions: role and efficacy. Thyroid 2004;14:125-131 
58. Monzani F, Goletti 0, Caraccio N, Del Guerra P, Ferdeghini $M$, Pucci $E$, et al. Percutaneous ethanol injection treatment of autonomous thyroid adenoma: hormonal and clinical evaluation. Clin Endocrinol (Oxf) 1992;36:491-497

59. Mazzeo S, Toni MG, De Gaudio C, Caramella D, Pinto F, Lencioni $\mathrm{R}$, et al. Percutaneous injection of ethanol to treat autonomous thyroid nodules. AJR Am J Roentgenol 1993;161:871-876

60. Di Lelio A, Rivolta M, Casati M, Capra M. Treatment of autonomous thyroid nodules: value of percutaneous ethanol injection. AJR Am J Roentgenol 1995;164:207-213

61. Tarantino L, Francica G, Sordelli I, Sperlongano P, Parmeggiani D, Ripa C, et al. Percutaneous ethanol injection of hyperfunctioning thyroid nodules: long-term follow-up in 125 patients. AJR Am J Roentgenol 2008;190:800-808

62. Kim DW, Rho MH, Park HJ, Kwag HJ. Ultrasonography-guided ethanol ablation of predominantly solid thyroid nodules: a preliminary study for factors that predict the outcome. $\mathrm{Br} \mathrm{J}$ Radiol 2012;85:930-936

63. Livraghi T, Paracchi A, Ferrari C, Bergonzi M, Garavaglia G, Raineri $P$, et al. Treatment of autonomous thyroid nodules with percutaneous ethanol injection: preliminary results. Work in progress. Radiology 1990;175:827-829

64. Tarantino L, Giorgio A, Mariniello N, de Stefano G, Perrotta A, Aloisio V, et al. Percutaneous ethanol injection of large autonomous hyperfunctioning thyroid nodules. Radiology 2000;214:143-148

65. Del Prete S, Russo D, Caraglia M, Giuberti G, Marra M, Vitale G, et al. Percutaneous ethanol injection of autonomous thyroid nodules with a volume larger than $40 \mathrm{ml}$ : three years of follow-up. Clin Radiol 2001;56:895-901

66. Gharib H, Hegedüs L, Pacella CM, Baek JH, Papini E. Clinical review: nonsurgical, image-guided, minimally invasive therapy for thyroid nodules. J Clin Endocrinol Metab 2013;98:3949-3957

67. Shin JE, Baek JH, Lee JH. Radiofrequency and ethanol ablation for the treatment of recurrent thyroid cancers: current status and challenges. Curr Opin Oncol 2013;25:14-19

68. Sung JY, Baek JH, Jung SL, Kim JH, Kim KS, Lee D, et al. Radiofrequency ablation for autonomously functioning thyroid nodules: a multicenter study. Thyroid 2015;25:112117

69. Paschke R, Hegedüs L, Alexander E, Valcavi R, Papini $\mathrm{E}$, Gharib $H$. Thyroid nodule guidelines: agreement, disagreement and need for future research. Nat Rev Endocrinol 2011;7:354-361

70. Papini E, Pacella CM, Hegedus L. Diagnosis of endocrine disease: thyroid ultrasound (US) and US-assisted procedures: from the shadows into an array of applications. Eur J Endocrinol 2014;170:R133-R146

71. Che Y, Jin S, Shi C, Wang L, Zhang X, Li Y, et al. Treatment of benign thyroid nodules: comparison of surgery with radiofrequency ablation. AJNR Am J Neuroradiol 2015;36:1321-1325
72. Seo SH, Kim TH, Kim SH, Lee SH, Kim JT, Park DW, et al. Predicting the size of benign thyroid nodules and analysis of associated factors that affect nodule size. Chonnam Med J 2015;51:97-101

73. Bernardi S, Stacul F, Michelli A, Giudici F, Zuolo G, de Manzini $\mathrm{N}$, et al. 12-month efficacy of a single radiofrequency ablation on autonomously functioning thyroid nodules. Endocrine 2017;57:402-408

74. Sohn YM, Hong SW, Kim EK, Kim MJ, Moon HJ, Kim SJ, et al. Complete eradication of metastatic lymph node after percutaneous ethanol injection therapy: pathologic correlation. Thyroid 2009;19:317-319

75. Vannucchi G, Covelli D, Perrino M, De Leo S, Fugazzola L. Ultrasound-guided percutaneous ethanol injection in papillary thyroid cancer metastatic lymph-nodes. Endocrine 2014;47:648-651

76. Suh CH, Baek JH, Choi YJ, Lee JH. Efficacy and safety of radiofrequency and ethanol ablation for treating locally recurrent thyroid cancer: a systematic review and metaanalysis. Thyroid 2016;26:420-428

77. Kim SY, Kim SM, Chang H, Kim BW, Lim CY, Lee YS, et al. Long-term outcomes of ethanol injection therapy for locally recurrent papillary thyroid cancer. Eur Arch Otorhinolaryngol 2017;274:3497-3501

78. Hay ID, Charboneau JW. The coming of age of ultrasoundguided percutaneous ethanol ablation of selected neck nodal metastases in well-differentiated thyroid carcinoma. J Clin Endocrinol Metab 2011;96:2717-2720

79. Goyal RM, Jonklaas J, Burman KD. Management of recurrent cervical papillary thyroid cancer. Endocrinol Metab Clin North Am 2014;43:565-572

80. Fontenot TE, Deniwar A, Bhatia P, Al-Qurayshi Z, Randolph GW, Kandil E. Percutaneous ethanol injection vs reoperation for locally recurrent papillary thyroid cancer: a systematic review and pooled analysis. JAMA Otolaryngol Head Neck Surg 2015;141:512-518

81. Jeong SY, Baek JH, Choi YJ, Lee JH. Ethanol and thermal ablation for malignant thyroid tumours. Int J Hyperthermia 2017;33:938-945

82. Goletti 0, Lenziardi M, De Negri F, Fiorini I, Lippolis PV, Cristofani $\mathrm{E}$, et al. Inoperable thyroid carcinoma: palliation with percutaneous injection of ethanol. Eur J Surg 1993;159:639-641

83. Isozaki T, Kiba T, Numata K, Saito S, Shimamura T, Kitamura $T$, et al. Medullary thyroid carcinoma with multiple hepatic metastases: treatment with transcatheter arterial embolization and percutaneous ethanol injection. Intern Med 1999;38:17-21

84. Akasu H, Shimizu K, Kitagawa W, Naito Z, Kawanami 0, Tanaka S. Histological study of papillary thyroid carcinoma treated with percutaneous ethanol injection therapy. Pathol Int 2002;52:406-409

85. Albanese G, Kondo KL. Pharmacology of sclerotherapy. Semin Intervent Radiol 2010;27:391-399 
86. Ahmed M, Brace CL, Lee FT Jr, Goldberg SN. Principles of and advances in percutaneous ablation. Radiology 2011;258:351369

87. Baek JH, Kim YS, Lee D, Huh JY, Lee JH. Benign predominantly solid thyroid nodules: prospective study of efficacy of sonographically guided radiofrequency ablation versus control condition. AJR Am J Roentgenol 2010;194:1137-1142

88. Ahn HS, Kim SJ, Park SH, Seo M. Radiofrequency ablation of benign thyroid nodules: evaluation of the treatment efficacy using ultrasonography. Ultrasonography 2016;35:244-252

89. Ko ES, Sung JY, Shin JH. Intralesional saline injection for effective ultrasound-guided aspiration of benign viscous cystic thyroid nodules. Ultrasonography 2014;33:122-127

90. Sung JY, Baek JH, Kim YS, Jeong HJ, Kwak MS, Lee D, et al. One-step ethanol ablation of viscous cystic thyroid nodules. AJR Am J Roentgenol 2008;191:1730-1733

91. Kim SM, Baek JH, Kim YS, Sung JY, Lim HK, Choi H, et al. Efficacy and safety of ethanol ablation for thyroglossal duct cysts. AJNR Am J Neuroradiol 2011;32:306-309

92. Cho YS, Lee HK, Ahn IM, Lim SM, Kim DH, Choi CG, et al. Sonographically guided ethanol sclerotherapy for benign thyroid cysts: results in 22 patients. AJR Am J Roentgenol 2000;174:213-216

93. Zingrillo M, Torlontano M, Ghiggi MR, D’Aloiso L, Nirchio V, Bisceglia $M$, et al. Percutaneous ethanol injection of large thyroid cystic nodules. Thyroid 1996;6:403-408

94. Zingrillo M, Torlontano M, Chiarella R, Ghiggi MR, Nirchio V, Bisceglia $M$, et al. Percutaneous ethanol injection may be a definitive treatment for symptomatic thyroid cystic nodules not treatable by surgery: five-year follow-up study. Thyroid 1999;9:763-767

95. Kim YJ, Baek JH, Ha EJ, Lim HK, Lee JH, Sung JY, et al. Cystic versus predominantly cystic thyroid nodules: efficacy of ethanol ablation and analysis of related factors. Eur Radiol 2012;22:1573-1578

96. Sung JY, Kim YS, Choi H, Lee JH, Baek JH. Optimum first- line treatment technique for benign cystic thyroid nodules: ethanol ablation or radiofrequency ablation? AJR Am J Roentgenol 2011;196:W210-W214

97. Del Prete S, Caraglia M, Russo D, Vitale G, Giuberti G, Marra $M$, et al. Percutaneous ethanol injection efficacy in the treatment of large symptomatic thyroid cystic nodules: tenyear follow-up of a large series. Thyroid 2002;12:815-821

98. Park NH, Kim DW, Park HJ, Lee EJ, Park JS, Park SI, et al. Thyroid cysts treated with ethanol ablation can mimic malignancy during sonographic follow-up. J Clin Ultrasound 2011;39:441-446

99. Zingrillo M, Ghiggi MR, Liuzzi A. A large, nonfunctioning parathyroid cyst recurring after aspiration and subsequently cured by percutaneous ethanol injection. J Clin Ultrasound 1996;24:378-382

100. Lee SJ, Ahn IM. Effectiveness of percutaneous ethanol injection therapy in benign nodular and cystic thyroid diseases: long-term follow-up experience. Endocr J 2005;52:455-462

101. Bennedbaek FN, Nielsen LK, Hegedüs L. Effect of percutaneous ethanol injection therapy versus suppressive doses of L-thyroxine on benign solitary solid cold thyroid nodules: a randomized trial. J Clin Endocrinol Metab 1998;83:830-835

102. Caraccio N, Goletti 0, Lippolis PV, Casolaro A, Cavina E, Miccoli $P$, et al. Is percutaneous ethanol injection a useful alternative for the treatment of the cold benign thyroid nodule? Five years' experience. Thyroid 1997;7:699-704

103. Lee JH, Kim YS, Lee D, Choi H, Yoo H, Baek JH. Radiofrequency ablation (RFA) of benign thyroid nodules in patients with incompletely resolved clinical problems after ethanol ablation (EA). World J Surg 2010;34:1488-1493

104. Rodríguez-Lomba E, Molina-López I, Parra-Blanco V, SuárezFernández R, Ciudad-Blanco C. Cutaneous implantation of papillary thyroid carcinoma secondary to percutaneous ethanol injection into nodal metastasis. J Eur Acad Dermatol Venereol 2018;32:e11-e13 